\title{
Causes and Countermeasures of Construction Project Costs beyond Budgeting
}

\author{
Ding Yuxian ${ }^{1, a}$, Jin Guohui ${ }^{1, b}$, Ding Yuxin ${ }^{1, c}$ \\ ${ }^{1}$ Inner Mongolia University of Science and Technology, Baotou, China, 014010 \\ ${ }^{2}$ Inner Mongolia University of Science and Technology, Baotou, China, 014010 \\ ${ }^{3}$ Hohhot Vocational School, Hohhot, China,010021 \\ amnb081223@126.com, bdingyuxian@imust.cn, mnb1223@163.com
}

\begin{abstract}
Keywords: costs beyond budgeting; causes; countermeasures
Abstract:It is an era of market economy, so all construction projects are of marketability and economy. The control of project costs involve various elements in the building economy, so it is a research question how to scientifically enhance the control of construction project costs to put the budget within a reasonable target framework. This paper discusses the causes and countermeasures of construction project costs beyond budgeting, and puts forward countermeasures by analyzing the causes and the existing problems.
\end{abstract}

As the important element of engineering cost management and the significant basis of construction investment, cost budget is critical in the engineering construction, which is usually accompanied with a certain deviation for various reasons. The phenomenon beyond budgeting happens sometimes, which affects the control of project cost to a large extent. Therefore, the causes and countermeasures of construction project costs beyond budgeting are studied to not only reasonably control the cost budget, but also contribute to the sustainable development of construction industry.

\section{Role of construction project cost in the practice}

In the construction engineering, the reasonable control of cost budget may ensure the smooth implementation of the project, with its importance mainly manifested in two aspects: on the one hand, it is the core link to realize the maximum interests; on the other hand, it is the premise and foundation of the smooth implementation of the project. The former may ensure that the project investment control is conducted within the approved budget, so as to reduce the project cost and to realize the maximum economic benefits; the latter may avoid reworking and design changes to some extent, so as to directly reduce the project cost and improve the benefit of the project, thus contributing to the following development of the project.

\section{Causes of construction project cost beyond budgeting}

The preliminary budget is prepared unreasonably. It is impossible for humans to work endlessly like robots. The budgeting personnel in charge of construction project cost may sometimes affect the budgeting rationality and scientificity for their emotions, attitudes and qualifications. There may be omitted or missed items in the budget prices for the negligence or indifference of budgeting personnel, so the preliminary budget is unable to reasonably reflect and correctly predict the actual expenses in one construction project. Therefore, the engineering budget lacking rationality and scientificity may not be used to guide and control the construction schedule and quality of all the participants, which may make the project cost beyond budgeting to a certain extent.

The construction project is changed arbitrarily in the construction process. Some construction projects are not demonstrated rigorously in the implementation process, which makes the 
engineering tasks urgent and the workload heavy; some are even constructed over design in order to reduce the construction term. Under those conditions, it is impossible to guarantee the reasonable cycle of design works, let along the rigorous demonstration of design plans. The drawings will be flawed, so modifications are inevitable. All above will make the project cost budget more difficult, thus easy to cause the project cost beyond budgeting.

The cost budget works are not valued enough. Based on investigations, some construction enterprises do not attach enough importance to the cost budget works. They tend to isolate the project cost budget, and only focus on the settlement works of bidding, bid invitation and completion. In the process of bid invitation, they just select the low price tender without considering the long-term economic interests, and conduct no effective control on the project cost in the actual construction stage.

The construction project cost is affected by policies, environments, markets and other factors. The markets of building materials, policies and various social environments are all constantly changing; the construction projects are usually large in time span, long in cycle and wide in range, so the staff often fails to predict policies, environments, markets and other factors in the future. As a result, although full consideration is given to the changes in markets and other objective factors, it is still impossible to make an accurate budget, and it is easy to go beyond the budget.

The supervision is improper. It is quite common that the project cost beyond budgeting is caused by the improper supervision during the construction. When reviewing the construction plan of the construction units, the supervisor shall urge the construction units to finish the tasks with less machinery and manpower as far as possible, and try their best to reduce and even avoid invalid management and labor on the premise of ensuring the quality. The supervisor with insufficient conscientiousness will cause arbitrary access; the delayed changes will lead to reworking, mechanical idle, lockout or slowdown, which will also increase the construction cost.

The development unit is not scientific and reasonable enough on project management. The reasonable and scientific management is most important for all projects. No project will be constructed smoothly without scientific management. Furthermore, the construction projects are always long in cycle, large in area and complex in processes. The construction conditions will not be reflected in time without proper management, thus causing waste of funds.

\section{Countermeasures of construction project cost beyond budgeting}

Strengthen the quality of budgeting personnel. The budgeting personnel will finish their works better when their qualities are improved. Budget is quite important in engineering cost, and the reasonable and scientific budgeting is critical for the effective control of engineering cost. Therefore, the control of project cost beyond budgeting is also of importance. The budgeting personnel shall pay attention to the following aspects if they want to do a good job:

Firstly, in the budgeting process, the budgeting personnel must have good sense of responsibility and professional ethics, and be familiar with the construction drawings, the fixed unit price and the bill of quantities of each item. They shall also conduct a field survey, and make overall arrangements in effective combination of the actual engineering with the construction drawings. Drawings are the soul of a project, so the scientific and reasonable project budget will be developed only with a full understanding on the significance of drawings in combination of actual conditions.

Secondly, the budgeting personnel must have a comprehensive and accurate knowledge of the construction site, the site standards, the market situations and the surrounding environments. They will become more proficient if making good preparations, resulting in more scientific and reasonable project budget.

Strengthen the design works and eliminate changes in the construction drawing. Before construction, the construction unit together with the design unit shall submit the replies on the intention of the development unit, the functions of the development project and in the earlier stage of project to the design unit which will design the project drawings according to the relevant policies and regulations, 
the instrument of ratification, and the project location by the development unit as careful as possible. At the same time, the development unit shall give enough design time, otherwise it is easy to cause design changes, thus resulting in an increase in the project cost.

Enhance the budget review process. To some extent, the budget review is the component of cost management. If the budget review process is added after the fulfillment of budgeting, the omission, repeating and miscount will be prevented to the largest extent, so as to improve the budgeting accuracy and control the cost beyond budgeting from the root.

Conduct scientific prediction on the market. In the budgeting of construction projects, although the budgeting personnel have made a full investigation, there are still many issues beyond budgeting. Therefore, the budgeting personnel shall conduct scientific prediction on the market at the basis of investigating the market situations. The price of building materials in the market is budgeted first in general. The budget results shall be flexible as far as possible, so as to adapt to the changing market. Only in this way, the budgeting amount will match the real project cost, thus avoiding the project beyond budgeting.

Strengthen budget control at the project implementation stage. The capitals are usually invested in the project at the implementation stage, which is not only the prolonging stage for bid invitation and bidding but also the elaboration phase of the contract. According to related research reports, the project cost is less affected at the implementation stage, accounting for about $10 \%$. The reduction of capital investment at this stage slightly influences the whole project cost, so most of the development units tend to pay less attention to the budget control at the implementation stage. In fact, at the implementation stage of any construction project where the manpower, material resources and financial resources are wasted seriously for the implementation, the project cost is usually increased for the following two causes:

One is the force majeure or objective factors out of control by humans, such as earthquake, storm, landslide, debris flow, government policy, war, etc. The other is the subjective factors such as the technical limitations, policy mistakes, contract changes by the supervision unit and the construction unit, and the cost increases caused by such factors can be controlled artificially in general. Furthermore, in the construction stage, the budgeting controller shall focus on the implementation of various budgeting items in the contract, and carry out the same as the key links to be controlled. In terms of the site access, measures shall be taken from the perspectives of economy, technology and contract. And professional personnel shall be designated for on-site supervision, including the normal measuring of main expenses in the original contract price and the settlement control in strict accordance with the settlement procedures, for the purpose of avoiding excessive payment in advance. The excessive payment shall be reported to the superior departments promptly once discovered, and the countermeasure shall be developed jointly to minimize the cost loss. Thus, only the valid access, supervision, pre-settlement audit systems will effectively ensure the quality of construction projects and enhance the positive economic benefits.

Strengthen the system construction to supervise all links from the root.

Firstly, formulate relevant rules and regulations, and determine the budgeting requirements executed strictly, thus preventing excessive administrative interventions.

Secondly, strengthen the supervision. The disciplinary inspection department, the supervision department and the auditing department shall supervise the whole process of the construction project. A person may be assigned specially to track or regularly inspect or irregularly test the of the whole process (initiation, approval, survey, design, budget, audit, verification, bid invitation and bidding, construction, and acceptance) of the project, so as to timely discover and correct the emerging problems, and stop up a loophole, thus implementing the prevention of violations into all aspects.

\section{Summary}

Subject to the development of economic construction, the competition of construction projects will become fiercer in the market. It is of importance to make the construction project cost and its control 
well, which is not only an important means to realize the project goals, but also a significant link to ensure the high quality engineering. In addition, it is conducive to the sustainable development of an enterprise.

\section{References}

[1] Wang Zhongting. Causes Analysis and Countermeasures of Construction Project Costs beyond Budgeting [J]. Technology Innovation and Application. 2014.4:243.

[2] Huang Peijie. Causes and Countermeasures of Construction Project Costs beyond Budgeting [J]. Manager' Journal. 2014 1:322.

[3] Meng Cheng. On Budget Control of Construction Project Cost [J]. Cities and Towns Construction in Guangxi. 2009 (9). 